\title{
Trends in the Southern Annular Mode from Observations and Reanalyses
}

\author{
Gareth J. MARShall \\ British Antarctic Survey, Natural Environment Research Council, High Cross, Madingley Road, Cambridge, United Kingdom
}

(Manuscript received 30 December 2002, in final form 16 May 2003)

\begin{abstract}
Several papers have described a significant trend toward the positive phase of the Southern Hemisphere annular mode (SAM) in recent decades. The SAM is the dominant mode of atmospheric variability in the Southern Hemisphere (SH) so such a change implies a major shift in the broadscale climate of this hemisphere. However, the majority of these studies have used NCEP-NCAR reanalysis (NNR) data, which are known to have spurious negative trends in SH high-latitude pressure. Thus, given that the SAM describes the relative atmospheric anomalies at mid- and high southern latitudes, these errors in the NNR data have the potential to invalidate the published findings on changes in the SAM. Therefore, it is important that a "true" benchmark of trends in the SAM is available against which future climate scenarios as revealed through climate models can be examined. In this paper this issue is addressed by employing an empirical definition of the SAM so that station data can be utilized to evaluate true temporal changes: six stations are used to calculate a proxy zonal mean sea level pressure (MSLP) at both $40^{\circ}$ and $65^{\circ} \mathrm{S}$ during 1958-2000. The observed increase in the difference in zonal MSLP between $40^{\circ}$ (increasing) and $65^{\circ} \mathrm{S}$ (decreasing) is shown to be statistically significant, with the trend being most pronounced since the mid-1970s. However, it is demonstrated that calculated trends in the MSLP difference between $40^{\circ}$ and $65^{\circ} \mathrm{S}$ and the SAM itself are exaggerated by a factor of 3 and 2, respectively, in the NNR. The SH high-latitude errors in the early part of this reanalysis are greatest in winter as are subsequent improvements. As a result, the NNR shows the greatest seasonal trend in the SAM to be in the austral winter, in marked contrast to observational data, which reveal the largest real increase to be in summer.

Equivalent data from two ECMWF reanalyses, including part of the new ERA-40 reanalysis, are also examined. It is demonstrated that ERA-40 provides an improved representation of SH high-latitude atmospheric circulation variability that can be used with high confidence at least as far back as 1973 - and is therefore ideal for examining the recent trend in the SAM — and with more confidence than the NNR right back to 1958.
\end{abstract}

\section{Introduction}

The principal mode of variability in the atmospheric circulation of the Southern Hemisphere ( $\mathrm{SH}$ ) extratropics and high latitudes is essentially a zonally symmetric or annular structure, with synchronous anomalies of opposite signs in Antarctica and the midlatitudes. It has variously been called the high-latitude mode (Rogers and van Loon 1982), the Antarctic Oscillation (Gong and Wang 1999), and the southern annular mode (SAM; Limpasuvan and Hartmann 1999). It will be referred to as the SAM throughout this paper. The SAM is equivalent barotropic in nature, being revealed as the leading empirical orthogonal function (EOF) in many atmospheric fields, including surface pressure, geopotential height, surface temperature, and zonal wind (see Thompson and Wallace 2000 and references therein). The SAM contributes a significant proportion of $\mathrm{SH}$ climate variability from high-frequency (Baldwin 2001)

Corresponding author address: Dr. Gareth J. Marshall, British Antarctic Survey, Natural Environment Research Council, High Cross, Madingley Road, Cambridge CB3 0ET, United Kingdom. E-mail: gjma@pcmail.nbs.ac.uk through to very low-frequency time scales (Kidson 1999). Modeling studies indicate that the SAM is also likely to drive the large-scale variability of the Southern Ocean (Hall and Visbeck 2002).

Several papers have reported a trend in the SAM toward its positive phase, that is, when pressures over Antarctica are relatively low compared to those in the midlatitudes. Such a trend will be described as an increase in the SAM in this paper. This trend entails a strengthening of the circumpolar vortex and intensification in the westerlies that encircle Antarctica. In the significant majority of these studies workers have utilized data from the National Centers for Environmental Prediction-National Center for Atmospheric Research (NCEP-NCAR) reanalysis (hereinafter NNR). Kidson (1999) derived his SAM as the third EOF in an 11month running mean 300-hPa streamfunction NNR data; his Fig. 14 showed a positive trend in the SAM from 1958 to 1997. Gong and Wang (1999) calculated the SAM empirically (see section 3) using NNR mean sea level pressure (MSLP) data from an identical period, and again demonstrated a general increase in the SAM (cf. their Fig. 4). Both studies indicated that the largest positive change occurred between the 1970s and 1980s, 
but also that the SAM was, on average, positive in the 1950s at the start of the NNR data examined. The change in the 1970 s corresponded to a marked shift in the SH atmospheric circulation noted by several authors (e.g., van Loon et al. 1993; Hurrell and van Loon 1994).

The SAM was also revealed as the first EOF of lowpass 500-hPa anomalies for 1949-98 NNR data in the work of Mo (2000). The negative trend in her Fig. 2a is because she defined the EOF in an opposite sense to that of the SAM, that is, positive when pressures at southern high latitudes are above average. Also note that the inclusion of the earlier NNR data in the calculation of the SAM gave a very strong increase in the SAM from 1950 to the mid-1960s, that is, the apparent MSLP difference between the SH extratropics and high latitudes was much less in the early 1950s than at any time since. Thompson et al. (2000) examined trends based on the leading EOF of $850-\mathrm{hPa}$ geopotential height from NNR data. Positive trends in the SAM existed in all but one month; in six months they were significant at the $<10 \%$ level but no clear seasonality existed. However, recently Thompson and Solomon (2002) showed that the greatest increases in the SAM, as defined by them using solely Antarctic radiosonde data, were in the austral summer and autumn (December-May). They postulated that changes in the SAM since the mid-1970s have been driven by the cooling of the Antarctic lower stratosphere, principally through ozone loss, a theory also previously proposed by the modeling studies of Sexton (2001) and Polvani and Kushner (2002). Thompson and Solomon (2002) suggested that the alteration in the SAM has contributed substantially to the observed warming in the Antarctic Peninsula and cooling over much of East Antarctica. This hypothesis has been corroborated by an analysis of a satellite-derived Antarctic surface temperature data series acquired from 1978 (Kwok and Comiso 2002). Furthermore, Marshall (2002a) showed that there has indeed been a statistically significant increase in tropospheric westerlies since the 1970s in the northern peninsula; but he also noted that most of the temperature rise on the western side of the peninsula occurred prior to any significant changes in the SAM.

Other studies have examined changes in the $\mathrm{SH}$ atmospheric circulation regime under predicted future "global warming" scenarios using coupled general circulation models (GCMs). Although a nonlinear dynamical perspective to climate prediction has been proposed (Palmer 1999) — in which the relative residence periods in a number of quasi-stationary atmospheric regimes will change-model predictions to date suggest that this is not applicable to the SH. Using different GCMs both Fyfe et al. (1999) and Kushner et al. (2001) showed that SH climate change patterns in MSLP and surface air temperature projected linearly, and almost exclusively, onto the SAM. The change was toward the positive phase of the SAM with interannual variability similar to the present day. Kushner et al. (2001) also dem- onstrated that this linear response extends at least to the tropopause, indicating that the broadly equivalent barotropic nature of the $\mathrm{SH}$ troposphere is preserved. Stone et al. (2001) examined the $\mathrm{SH}$ atmospheric response both to changes in climate (increasing $\mathrm{CO}_{2}$ ) and to future equilibrium climates (with higher levels of $\mathrm{CO}_{2}$ than at present); they revealed that while MSLP projected strongly onto the SAM in the change scenarios, this did not occur in the equilibrium scenarios. The authors interpreted this result as an atmosphere-only response during periods of climate change with the SAM reverting to its original state once the climate evolved, with the atmosphere-ocean-sea ice response being largely unrelated to the SAM. Thus, one might argue that as reported recent changes in the SAM demonstrate similar trends to those predicted by GCMs under global warming climate change scenarios, they indicate that anthropogenic climate change may already be under way.

However, there is a fundamental problem with the results pertaining to recent changes in the SAM obtained by those authors that use the NNR data in their studies. This is because other workers have demonstrated clearly that significant errors exist in the pressure fields at high southern latitudes in the NNR (Hines et al. 2000; Marshall and Harangozo 2000). Figure 2 of Hines et al. (2000) indicates marked temporal decreases in MSLP south of $\sim 50^{\circ} \mathrm{S}$ in the NNR, which are greatest at $65^{\circ} \mathrm{S}$, the latitude of the circumpolar trough. Here, zonal MSLP has decreased by $8 \mathrm{hPa}$ in the decade 1989-98 compared to 1949-58. Comparison against station observations showed the NNR trends to be spurious-see Fig. 7 of Hines et al. (2000) and Figs. 2 and 3 of Marshall and Harangozo (2000) for examples-and occurring principally due to the general improvement in the accuracy of the NNR through time in the Antarctic region. These two papers concluded that significant periods of missing station observations in the NNR prior to the advent of global telecommunication system (GTS) derived data in 1967 was the major problem: the NNR model tends to drift toward its climatology when not sufficiently constrained by synoptic data. The marked decline in MSLP at $65^{\circ} \mathrm{S}$ toward more realistic values coincides with a steadily increasing skill in the $\mathrm{SH}$ in the NNR (see Fig. 7 of Kistler et al. 2001); however significant errors in the NNR do continue into the 1990s (Marshall and Harangozo 2000). Thompson et al. (2000) state that because of "The questionable reliability of the trends in the NCEP-NCAR in the region ... it is difficult to estimate the component of the observed trends that is linearly congruent with the annular mode." Problems with NNR pressures also exist throughout the troposphere at high southern latitudes (Marshall 2002b) although, following the advent of satellite sounder data assimilation in 1979, Thompson and Solomon (2002) believe that the NNR produces a reasonable facsimile of the SAM. The net result of the improvements in the 
NNR is an unrealistic increase in the difference between pressure at SH mid- and high latitudes in the reanalysis.

In this study we are interested in calculating the "true" changes in the SAM-an obviously "urgent research issue" (Kushner et al. 2001) so that we may properly interpret and evaluate GCM output. Subsequently, we can ascertain the impact that errors in the NNR have caused in previously calculated trends in the SAM; have they simply exaggerated the magnitude of the trend toward the positive phase or actually produced a spurious trend where none exists? For example, Kushner et al. (2001) say that trends they simulated in a GCM were weaker than that given by Thompson et al. (2000) and not statistically significant. Other evidence hinting that the trends in the SAM derived from the NNR may be inaccurate comes from the study of Karoly et al. (1996). These authors produced EOF analyses of the $\mathrm{SH}$ extratropics and high latitudes based on MSLP and surface pressure data from 62 stations from 1955 to 1985. Their second EOF was similar to the SAM and this demonstrated no significant trend over the entire period examined (cf. their Fig. 3b). However, a trendequivalent to being toward the positive phase of the SAM - is observed beginning in the mid-1970s, as also revealed in the NNR data (Gong and Wang 1999).

In order to calculate a true unbiased measure of the SAM we utilize the empirical definition proposed by Gong and Wang (1999), which is based upon the zonal MSLP at $40^{\circ}$ and $65^{\circ} \mathrm{S}$. This definition is adjusted to values based on the mean of six station records near each of the two latitudes used in the definition, for which good long-term records-the period 1958-2000 is used-are available. The exact methodology is described in section 3 of this paper, which follows a description of all the datasets used in the study (section 2). In addition to analyzing the SAM, the zonal MSLP at $40^{\circ}$ and $65^{\circ} \mathrm{S}$ is examined separately; this allows us to compare the observations against two further reanalyses produced by the European Centre for MediumRange Weather Forecasts (ECMWF), which are, at least currently, much shorter in length than the NNR. One of these, ERA-40, will eventually encompass the period from 1958 to 2001 but when this manuscript was written was still in production. In the results, in section 4 , the three reanalyses are compared to the zonal MSLP observations at $40^{\circ}$ and $65^{\circ} \mathrm{S}$ in terms of their mean bias and root-mean-square (rms) errors; particular attention is paid to ERA-40 as this study represents one of the first to assess its utility in SH climate studies. And, of course, long-term trends in the SAM from observations and NNR data are compared. The summarizing discussion (section 5) focuses upon (i) the calculated "real" trends in the SAM, based upon the observational data and how they relate to other studies of the SH atmospheric circulation; (ii) the nature and magnitude of the errors at high southern latitudes and in the SAM inherent in the NNR data; and (iii) an appraisal of ERA-40 for long-term studies of the SAM and MSLP at high southern latitudes.

\section{Data}

\section{a. The NCEP-NCAR reanalysis}

The NNR project is described in detail by Kalnay et al. (1996) and Kistler et al. (2001). The reanalysis model is based on the NCEP operational model of 10 January 1995 with a reduced horizontal resolution of T62 $(\sim 210$ $\mathrm{km})$ and 28 vertical levels. As the reanalysis uses data types additional to the operational analysis a more complex quality control system was introduced. Satellite sounder data were first assimilated into the reanalysis in March 1975 but principally comprise the Television Infrared Observation Satellite (TIROS) Operational Vertical Sounder (TOVS) data from 1979 onward: over the Southern Ocean these were the first systematic observations available to the reanalysis and led to a major improvement in Southern Hemisphere forecasts (Kistler et al. 2001).

MSLP is described as a class A output variable (Kalnay et al. 1996), that is, it is strongly determined by observed data. As noted in the introduction, other studies have demonstrated that spurious trends exist in the NNR MSLP at high southern latitudes because observations have not been assimilated. An additional potential problem with the NNR concerns the Australian pseudo-observations of sea level pressure (PAOBS) - the product of human analysts who estimate sea level pressure based on satellite imagery, conventional data, and time continuity - that were assimilated with a $180^{\circ}$ error in longitude between 1979 and 1992. Due to the sparse nature of data at high southern latitudes this had its greatest impact between $45^{\circ}$ and $60^{\circ} \mathrm{S}$ but with a decreasing influence thereafter toward the South Pole. However, it is not believed that this will impact the present study greatly because the significance of the errors declines rapidly from synoptic to monthly time scales (more information available online at http:// wesley.wwb.noaa.gov/paobs/paobs_1.html). The NNR data were obtained on a $2.5^{\circ}$ latitude-longitude grid.

\section{b. The ERA-15 reanalysis}

The ERA-15 project was a reanalysis of $15 \mathrm{yr}$ of meteorological data from 1979 to 1993 (Gibson et al. 1996). The spectral model used for ERA-15 had a horizontal resolution of T106 (equivalent to $\sim 100 \mathrm{~km}$ ) and 31 vertical levels. The data were obtained on a reduced Gaussian N80 grid (160 latitudinal cells $\times 320$ longitudinal cells at the equator reducing to 18 at the poles) such that all model grid cells are of similar area. ERA15 also has problems in Antarctica (Bromwich et al. 2000), although as this study indicates, the effects on MSLP are relatively minor. 
TABLE 1. The stations used to produce the SAM from observations. The number of missing months refers to the 1958-2000 period.

\begin{tabular}{lccc}
\hline \hline & Lat $\left({ }^{\circ} \mathrm{S}\right)$ & Lon $\left({ }^{\circ} \mathrm{E}\right)$ & $\begin{array}{c}\text { Missing data } \\
(\mathrm{months})\end{array}$ \\
\hline Marion Island & 46.9 & 37.9 & 3 \\
Ile Nouvelle Amsterdam & 37.8 & 77.5 & 21 \\
Hobart & 42.9 & 147.3 & 0 \\
Christchurch & 43.5 & 172.6 & 0 \\
Valdivia & 39.6 & -73.1 & 0 \\
Gough Island & 40.4 & -9.9 & 0 \\
Novolazarevskaya & 70.8 & 11.8 & 37 \\
Mawson & 67.6 & 62.9 & 0 \\
Mirny & 66.6 & 93.0 & 0 \\
Casey & 66.3 & 110.5 & 2 \\
Dumont D'urville & 66.7 & 140.0 & 11 \\
Faraday/Vernadsky & 65.2 & -64.3 & 0 \\
\hline
\end{tabular}

\section{c. The ERA-40 reanalysis}

ERA-40 is the latest ECMWF reanalysis and encompasses the 44-yr period from mid-1957 to 2001. The reanalysis is being undertaken in three separate stages, or streams, each of which have different data types available to them and hence require different assimilation techniques. Stream 1 is from 1987 to 2001, Stream 2 is from 1957 to 1972 , and Stream 3 is from 1972 to 1988. At the time of this study, all three streams were currently running. Unfortunately, an error has been discovered in Stream 1 due to, among other things, an inadequate algorithm for the assimilation of High-Resolution Infrared Sounder (HIRS) radiances. This has led to a cold bias over sea ice regions in both the Arctic and Antarctic and it has been decided that Stream 1 will be, at least partially, rerun. Therefore, only data from Streams 2 and 3 are employed in this work; at the time of analysis the following $22 \mathrm{yr}$ were available from these two streams: Stream 2 (1958-69) and Stream 3 (197382). ERA-40 is run at T159 and is linearly reduced to the Gaussian N80 grid, described in section 2b. Some enhancements over ERA-15 that will impact the MSLP field include the capability to assimilate hourly surface data where available through three-dimensional variational (3DVAR) and First Guess at Appropriate Time (FGAT) techniques, a much higher resolution in the planetary boundary layer and the use of PAOBS. (Further details of ERA-40 can be found online at http:// www.ecmwf.int/research/era/Project/.)

\section{d. Observations}

The numerical definition of the SAM by Gong and Wang (1999) is as follows:

$$
\mathrm{SAM}=P_{40^{\circ} \mathrm{S}}^{*}-P_{65^{\circ} \mathrm{S}}^{*},
$$

where $P_{40^{\circ} \mathrm{s}}^{*}$ and $P_{65^{\circ} \mathrm{s}}^{*}$ are the normalized monthly zonal MSLP at $40^{\circ}$ and $65^{\circ} \mathrm{S}$, respectively. These two latitudes were chosen by those authors based on the magnitude $(-0.59)$ and statistical significance $(<1 \%)$ of the correlation coefficient between them (see their Fig. 2). In

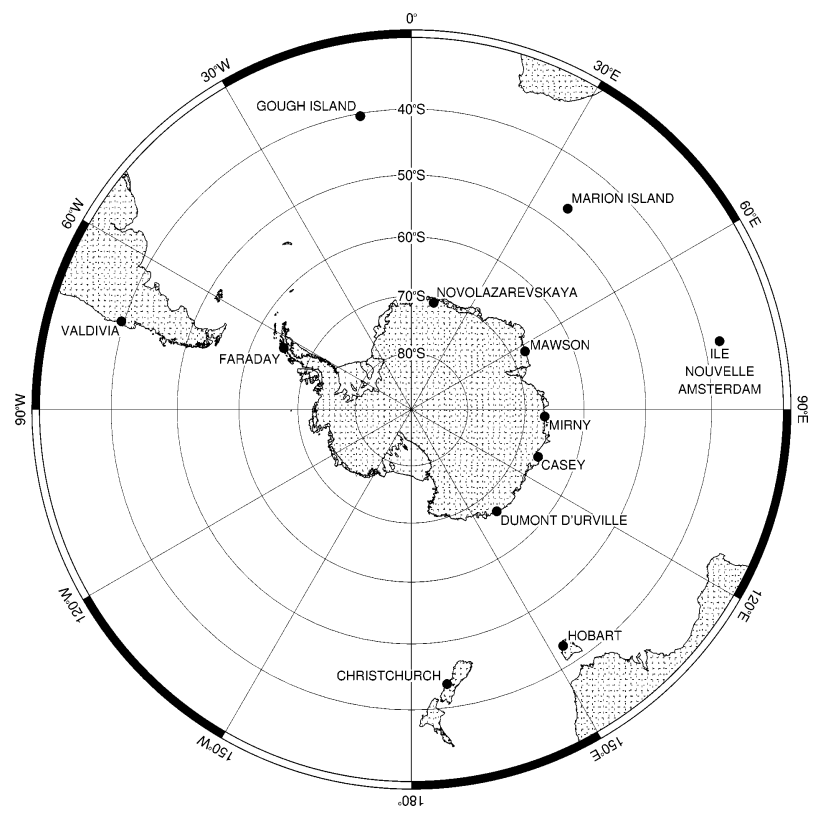

FIG. 1. Stations used to compute a zonal mean at $40^{\circ}$ and $65^{\circ} \mathrm{S}$.

this study we modify this definition slightly, and use the mean MSLP observations from six stations located approximately at each of the two latitudes to provide a proxy zonal mean: hence, utilizing this version of Eq. (1), we are able to calculate a SAM from observations against which we can compare the reanalyses. The coordinates of the stations are given in Table 1 and their distribution shown in Fig. 1. The stations were chosen for the following criteria: (i) a location close to the latitude band, (ii) taken as a group they provided as good a spread of longitudes as possible, and (iii) a reasonably long time series of monthly data with few missing values was available. The first two criteria are obviously influenced by the spatial distribution of landmasses and islands in the southern mid- and high latitudes. For example, Fig. 1 indicates a dearth of stations in the Pacific sector at both $40^{\circ}$ and $65^{\circ} \mathrm{S}$, due to a lack of appropriate island locations in the former case and inaccessibility to potential sites in the latter. The impact of the lack of Pacific data is difficult to quantify. However, numerical weather prediction analyses generally indicate a climatological low in the Pacific region of the circumpolar trough (e.g., King and Turner 1997, their Fig. 3.15), suggesting that the proxy zonal mean at $65^{\circ} \mathrm{S}$ in this paper may be slightly too high on average. Moreover, with the exception of the Antarctic Peninsula, much of the Antarctic coastline lies beyond $65^{\circ} \mathrm{S}$ so the stations representing this latitude are necessarily located farther south. The fact that most Antarctic stations did not commence observations until the International Geophysical Year (IGY) of 1957/58 imposes a limit on the length of SAM time series available from observations. Thus, the 43-yr period from 1958 to 2000 was chosen for this analysis. 
It should be noted that the missing data from Novolazarevskaya (see Table 1) occur because this station did not become operational until January 1961, after which the series is complete. Other stations in the same region, which began earlier, were considered too far south or had less complete observations. All Antarctic data were derived from the Reference Antarctic Data for Environmental Research (READER) project (Turner et al. 2003, manuscript submitted to J. Climate; more information available online at http://www.antarctica. ac.uk/met/READER), which uses 6-hourly synoptic data to generate monthly mean values of MSLP. P. D. Jones of the Climatic Research Unit, University of East Anglia, kindly provided data for the stations at $40^{\circ} \mathrm{S}$. Most of these data are derived from CLIMAT messages, and a few gaps exist, especially at Ile Nouvelle Amsterdam, when this information has been missing from GTS transmissions. For those months when a station had missing data, the value was determined using multiple regression equations for each individual calendar month; MSLP observations from the other stations at that latitude were used as five predictor variables.

\section{Methodology}

For the SAM derived from observations to be considered a reasonable facsimile of the SAM defined by Eq. (1) it is obviously necessary to check that the two "proxy" zonal means derived from six points have similar characteristics to the true zonal means. This comparison was undertaken principally using NNR data obtained on a $2.5^{\circ}$ latitude-longitude grid. The true zonal mean was simply the mean of the 144 points along the appropriate parallel, while data equivalent to station observations were determined by interpolating the NNR MSLP fields to the station location to the nearest $0.1^{\circ}$ latitude-longitude. To help assess the agreement between the two estimates, diagnostic scatterplots were used (e.g., Bland and Altman 1986). Figure 2a shows the difference in pressure between the two estimates of zonal mean against time. The data reveal that while there are significant differences - a mean bias of $-1.6 \mathrm{hPa}$ at $40^{\circ} \mathrm{S}$ (black dots) and $+3.7 \mathrm{hPa}$ at $65^{\circ} \mathrm{S}$ (white dots) exists in the values derived from the six station locations-there is no significant trend in the magnitude or variability of this difference through time. In Fig. $2 b$ the difference between the two estimates is plotted against their mean value. There is clearly no trend with MSLP at $40^{\circ} \mathrm{S}$ : the black circles form a near-circular cluster. For the differences at $65^{\circ} \mathrm{S}$ there is a slight tendency for greater differences to be associated with greater MSLP values and vice versa. Although this relationship is not statistically significant, it will nevertheless have a potential impact on any long-term trend in the SAM; for example, if there is a decrease in MSLP at $65^{\circ} \mathrm{S}$ through time then the resultant trend in the SAM will be too small. The bias will also vary seasonallygreatest (least) in winter (summer) when MSLP is high-
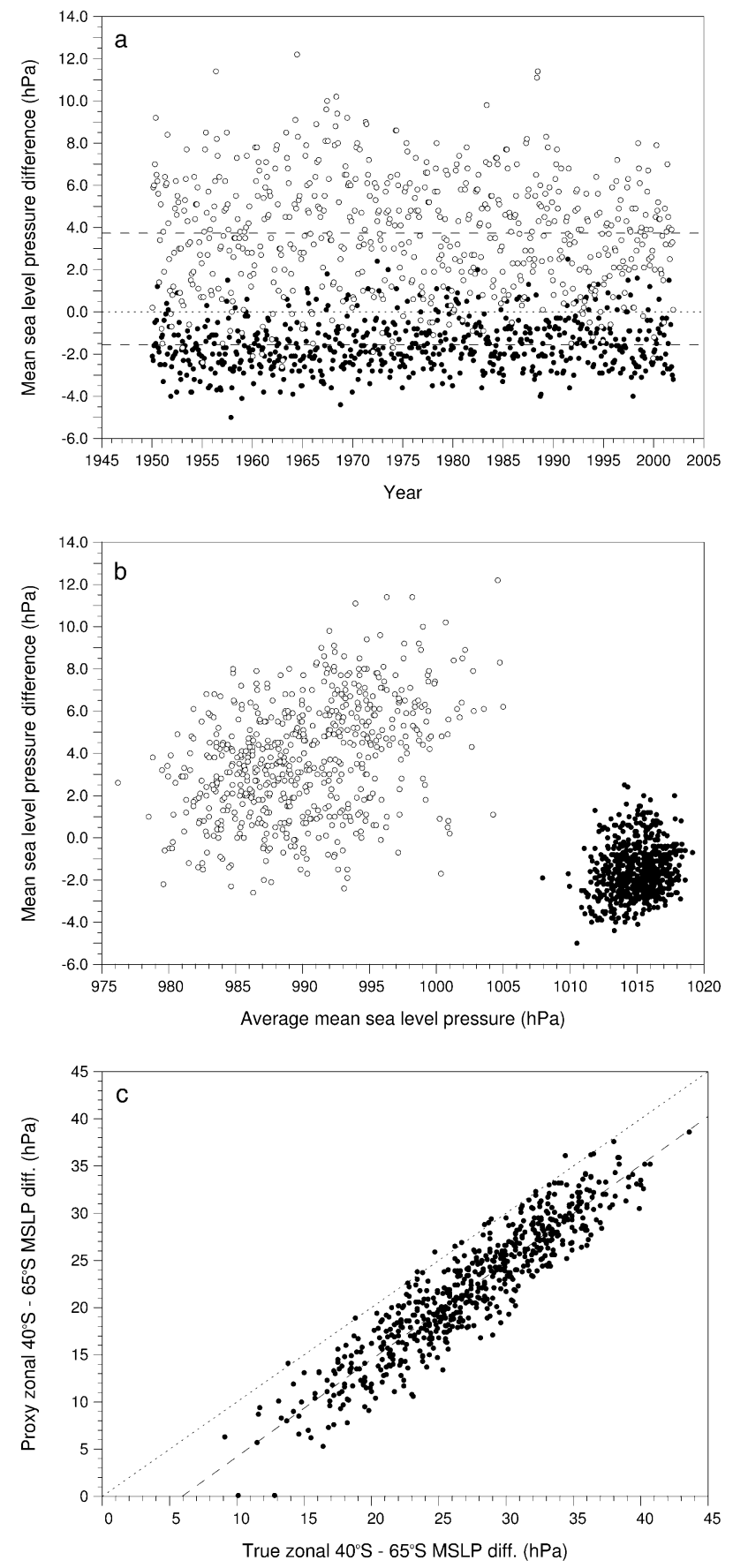

FIG. 2. A comparison of zonal MSLP difference in NNR data derived from six station locations (proxy zonal mean) minus that derived from 144 latitudinal grid points (true zonal mean): (a) vs time and (b) vs the average MSLP determined from the two methods. Black dots are for $40^{\circ}$ and white dots for $65^{\circ} \mathrm{S}$. (c) A comparison of the difference in the $40^{\circ}-65^{\circ} \mathrm{S}$ zonal MSLP using true and proxy values; although there is a negative bias in the proxy values [located to the right of the (dotted) $y=x$ line], the gradient of the fitted (dashed) line is also 1. 


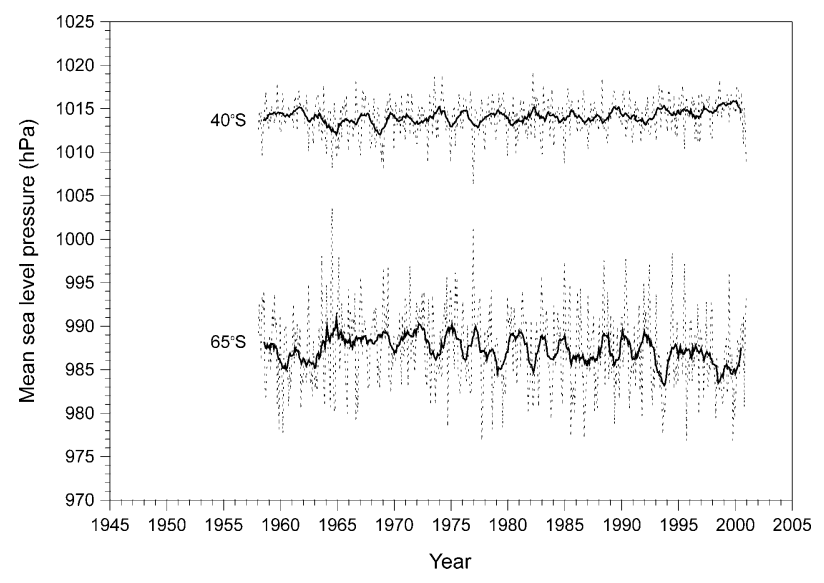

FIG. 3. Monthly zonal MSLP at $40^{\circ}$ and $65^{\circ} \mathrm{S}$ derived from station observations (dotted line) with running 12-month filter (solid line).

est (lowest)—but this aspect does not impact directly the results described in this study. This issue is discussed further in the results section. The standard deviations of the two estimates are similar at each latitude band; 1.7 against $1.9 \mathrm{hPa}$ at $40^{\circ}$ and 5.0 against $6.0 \mathrm{hPa}$ at $65^{\circ} \mathrm{S}$. Finally, it is essential that the temporal variation of the proxy zonal mean must closely match that of the zonal mean. Correlation coefficients between the two monthly MSLP time series are 0.78 at $40^{\circ}, 0.90$ at $65^{\circ} \mathrm{S}$ and, most importantly given Eq. (1), 0.93 for the $40^{\circ}-$ $65^{\circ} \mathrm{S}$ MSLP difference (see the gradient of the fitted line in Fig. 2c). Thus, in this latter case, the station-based proxy zonal mean is able to explain more than $86 \%$ of the monthly variance in the true zonal mean. We conclude that using the six observations at each latitude band provides an appropriate methodology for comparing the SAM in reanalysis datasets and observations.

In this study trends were calculated using standard least squares adjustment. Significance was determined accounting for autocorrelation (see, e.g., Trenberth 1984 for the methodology, which gives a somewhat conservative estimate of significance). As the temporal trend of the predictor value, time, is not random, the methodology is altered in that the degree of autocorrelation is computed using the residuals of the regression equation rather than the two time series. The number of effectively independent samples $n_{\text {eff }}$ rather than the number of actual samples $n$ is used in the Student's $t$ test for significance. Confidence intervals shown for the trends-(see section 8.3.7 of von Storch and Zwiers 1999) — are calculated at the $95 \%$ level with the degrees of freedom based on $n_{\text {eff }}$. Due to the differing effects of autocorrelation on the trends and confidence intervals, using $n_{\text {eff }}$ in the calculation of the latter is likely to provide a slight overestimate (H. Grubb, Statistical Service Centre, University of Reading, 2001, personal communication).

All further use of the terms zonal mean and SAM in this paper assumes that they are, or have been derived from, the two proxy zonal means-calculated from ob-

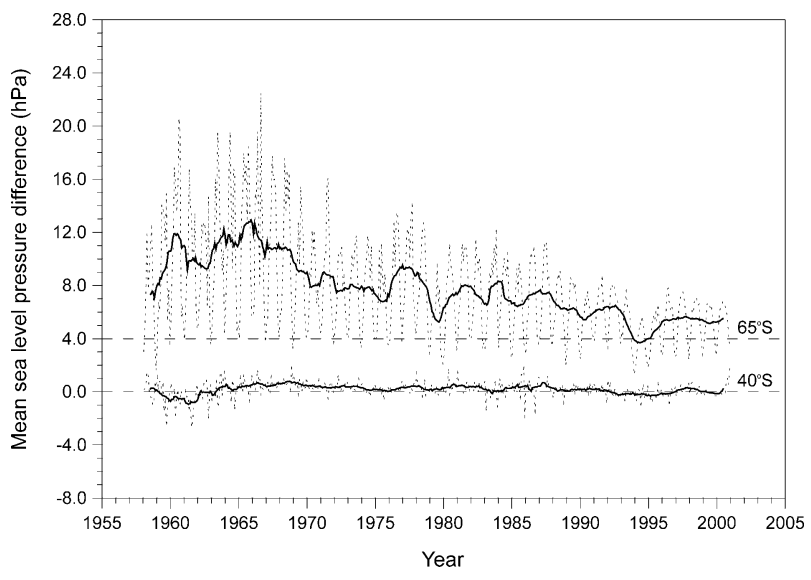

FIG. 4. Differences in zonal MSLP at $40^{\circ}$ and $65^{\circ} \mathrm{S}$ as derived from NNR data and observations. Note that the data for $65^{\circ} \mathrm{S}$ are offset by $+4 \mathrm{hPa}$.

servations or equivalent reanalysis data (i.e., interpolated to station locations) - unless explicitly stated otherwise.

\section{Results}

Due to the incomplete or comparatively short nature of the ECMWF reanalyses available at the time of this study, a comparison of these against observations and the NNR was undertaken using the two sets of zonal mean data rather than the SAM itself, which is based on long-term normalized anomalies [cf. Eq. (1)]. Trends in the zonal MSLP at the two latitude bands derived from station observations are statistically insignificant, and are equivalent to changes of only +0.02 and -0.04 $\mathrm{hPa} \mathrm{yr}^{-1}$ at $40^{\circ}$ and $65^{\circ} \mathrm{S}$, respectively. Closer inspection of Fig. 3 reveals that changes in these two zonal means have increased most since the late 1970s-the trends from 1980 to 2000 are more than twice the longer-term trends, being +0.06 and $-0.09 \mathrm{hPa} \mathrm{yr}^{-1}$ at $40^{\circ}$ and $65^{\circ} \mathrm{S}$, respectively. The correlation coefficient between the two 516 month mean zonal MSLP time series is -0.53 , statistically significant at well below the $1 \%$ level.

The differences in the zonal mean as calculated from observations and equivalent NNR and ECMWF data are shown in Figs. 4 and 5, respectively, with the mean and rms differences for the appropriate periods provided in Table 2. Unsurprisingly, given the sparse distribution of observations at high southern latitudes prior to the availability of satellite sounder data in the mid-1970s, it is clear that the reanalyses are better at capturing the zonal MSLP at $40^{\circ}$ than $65^{\circ} \mathrm{S}$. All three reanalyses do a good job at characterizing the mean values and variability in MSLP at the lower latitude. Note that between 1958 and 1969 the NNR is superior to ERA-40, while the latter is marginally better for 1973-82. The differences between the NNR and ERA-15 versus observations for 1979-93 are essentially identical.

At $65^{\circ} \mathrm{S}$ the reanalyses are much poorer, especially 


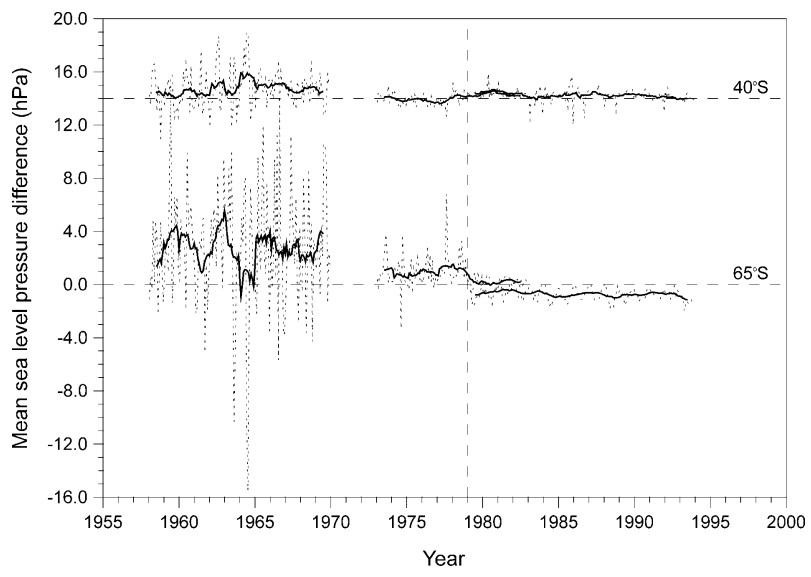

FIG. 5. Differences in zonal MSLP at $40^{\circ}$ and $65^{\circ} \mathrm{S}$ as derived from ECMWF data and observations. ERA-40 data encompass the periods from 1958 to 1966 and from 1973 to 1979 and ERA-15 data from 1979 to 1993 . Note that the data for $40^{\circ} \mathrm{S}$ are offset by $+12 \mathrm{hPa}$.

the NNR. In Fig. 4 it is apparent that in the calculation of the zonal mean there is a distinct annual cycle in the difference between this reanalysis and observations. In summer the difference is approximately zero or indeed slightly negative; a mean difference of $-0.5 \mathrm{hPa}$ in December for the 1958-2000 period. The maximum difference occurs in winter, peaking in August with a mean figure of $+6.3 \mathrm{hPa}$. Seasonal variation in the trends in NNR MSLP at high southern latitudes was also noted by Hines et al. (2000), who considered that the fewer Antarctic observations during the polar night (winter) was a contributing but not solely responsible factor. The greater trend in winter is apparent in Fig. 4, which shows that the summer bias has remained relatively constant whereas a clear decrease in the winter bias has led to the improved overall bias and rms errors in the NNR data through time. Although ERA-40 is better than NNR for the 1958-66 period there are still some very large single discrepancies (spikes) in the zonal MSLP, the largest being $-15.5 \mathrm{hPa}$ in July 1964 (cf. Fig. 5). To investigate these phenomena further the MSLP difference plots for the six individual stations used to produce the zonal mean were examined. Examples from the Novolazarevskaya and Mirny stations are shown in Figs. $6 \mathrm{a}$ and $6 \mathrm{~b}$, respectively. The other four stations all reveal broadly similar MSLP differences to Mirny whereas No-
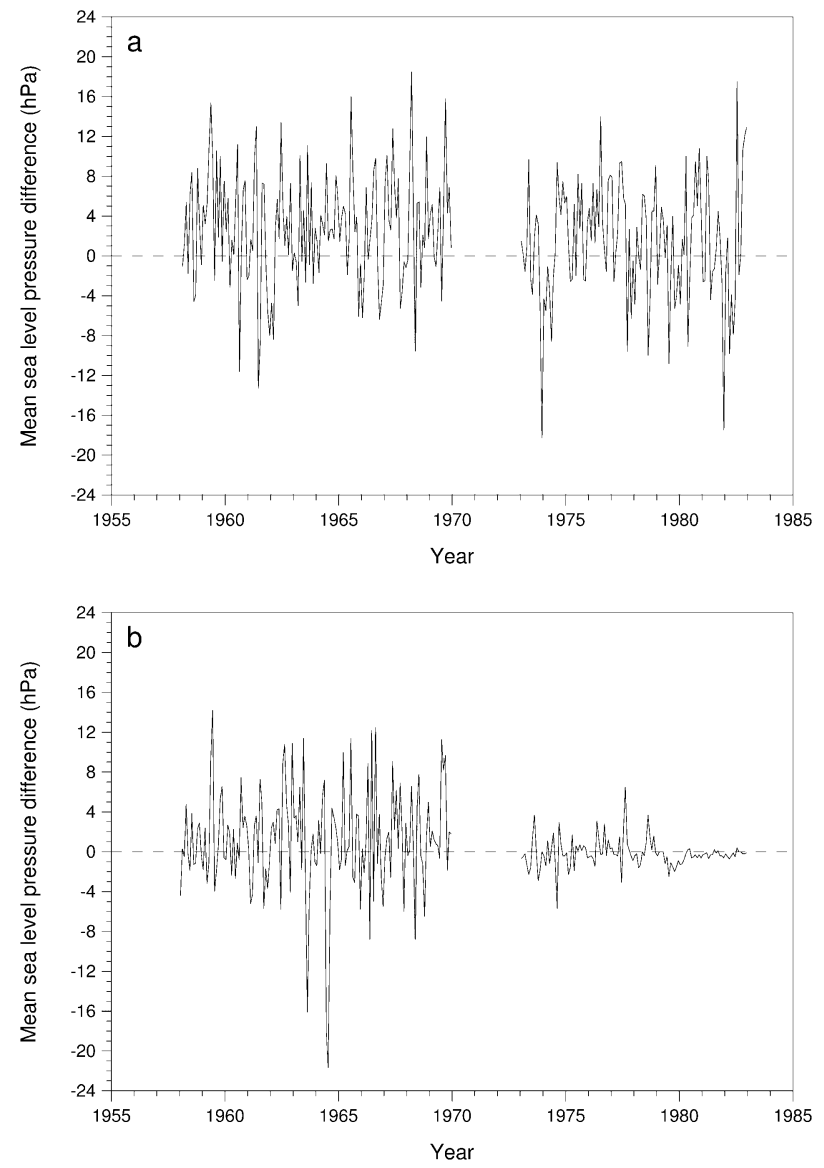

FIG. 6. Differences in monthly MSLP between ERA-40 and observations at (a) Novolazarevskaya and (b) Mirny stations.

volazarevskaya is somewhat dissimilar. For example, while Mirny and the other four stations all have a marked negative bias in MSLP in ERA-40 in July 1964 and, to a lesser extent, August 1963-hence, the negative spikes observed in Fig. 5-equivalent biases at Novolazarevskaya are actually positive.

However, for the 1973-82 period ERA-40 has improved considerably at $65^{\circ} \mathrm{S}$, with a mean positive bias of $<1 \mathrm{hPa}$ and deviations away from this being much smaller than previously (cf. Fig. 5 and Table 2). Much of this advance is probably due to the assimilation of Vertical Temperature Profile Radiometer (VTPR) sound-

TABLE 2. Mean and rms difference (in parentheses) in the zonal MSLP at $40^{\circ}$ and $65^{\circ} \mathrm{S}$ compared to observations. Units are $\mathrm{hPa}$.

\begin{tabular}{|c|c|c|c|c|}
\hline Source & 1958-2000 & $1958-69$ & $1973-82$ & 1979-93 \\
\hline \multicolumn{5}{|l|}{$40^{\circ} \mathrm{S}$} \\
\hline NNR & $+0.17(0.61)$ & $+0.15(0.85)$ & $+0.29(0.47)$ & $+0.21(0.55)$ \\
\hline ERA-40 & - & $+0.44(1.21)$ & $+0.09(0.44)$ & - \\
\hline ERA-15 & - & - & - & $+0.25(0.52)$ \\
\hline \multicolumn{5}{|l|}{$65^{\circ} \mathrm{S}$} \\
\hline NNR & $+3.74(5.34)$ & $+6.39(7.98)$ & $+3.67(4.77)$ & $+2.64(3.63)$ \\
\hline ERA-40 & - & $+1.78(3.93)$ & $+0.68(1.28)$ & - \\
\hline ERA-15 & - & - & - & $-0.72(0.87)$ \\
\hline
\end{tabular}


TABLE 3. Annual and seasonal trends in the difference between the proxy zonal mean at $40^{\circ}$ and $65^{\circ} \mathrm{S}$ from observations and proxy and true zonal NNR data from 1958-2000. Units are hPa century ${ }^{-1}$. The second figure represents the $95 \%$ confidence intervals of the trend. Trends significant at the $<1 \%,<5 \%$, and $<10 \%$ level are marked with an a, b, or c superscript, respectively.

\begin{tabular}{|c|c|c|c|c|c|}
\hline Source & Annual & Autumn (MAM) & Winter (JJA) & Spring $(\mathrm{SON})$ & Summer (DJF) \\
\hline Observations & $+6.2 \pm 6.3^{\mathrm{c}}$ & $+8.2 \pm 11.0$ & $+7.1 \pm 11.9$ & $+0.0 \pm 11.1$ & $+10.5 \pm 13.5$ \\
\hline NNR (proxy) & $+20.5 \pm 7.6^{\mathrm{a}}$ & $+25.5 \pm 11.8^{\mathrm{a}}$ & $+28.2 \pm 14.4^{\mathrm{a}}$ & $+14.5 \pm 10.4^{\mathrm{a}}$ & $+15.2 \pm 12.8^{\mathrm{b}}$ \\
\hline NNR (true) & $+16.9 \pm 7.2^{\mathrm{a}}$ & $+21.4 \pm 11.8^{\mathrm{a}}$ & $+22.5 \pm 12.8^{\mathrm{a}}$ & $9.7 \pm 11.7^{c}$ & $+15.4 \pm 12.2^{b}$ \\
\hline
\end{tabular}

ing data (which are not utilized by the NNR), with a further improvement from 1979 onward following the introduction of TOVS (cf. Figs. 4 and 6b). For this period the six stations near $65^{\circ} \mathrm{S}$ can be similarly divided into two groups as before; Fig. 6 indicates that at the location of the majority of these stations-as represented by Mirny-ERA-40 characterizes MSLP variability very well but at Novolazarevskaya the reanalysis is no better than in the earlier period. The NNR has also improved from the earlier period examined but is still poor; it has a larger mean bias and similar rms error in 1973-82 than ERA-40 during 1958-69. Even in the 1979-93 period the mean bias in the NNR at $65^{\circ} \mathrm{S}$ is greater than ERA-40 during 1958-69; the rms error is slightly better but still 3 times that observed in the ERA40 data for 1973-82. ERA-15 has a very small ( -0.7 $\mathrm{hPa}$ ) consistent bias in the zonal MSLP at $65^{\circ} \mathrm{S}$. Figure 5 reveals a small annual cycle in the difference from observations in this reanalysis. Like the NNR data, the largest (smallest) deviation is in winter (summer) data.

The SAM, of course, is a means of quantifying differences in atmospheric anomalies at $\mathrm{SH}$ extratropical and high latitudes. Therefore, trends in the difference between zonal MSLP at $40^{\circ}$ and $65^{\circ} \mathrm{S}$ were examined. This was undertaken on an annual and seasonal basis for both observations and NNR data for the 1958-2000 period, with the results given in Table 3. Both datasets reveal a statistically significant positive trend in the difference, which is toward the positive phase of the SAM. However, the NNR trend is approximately 3 times larger

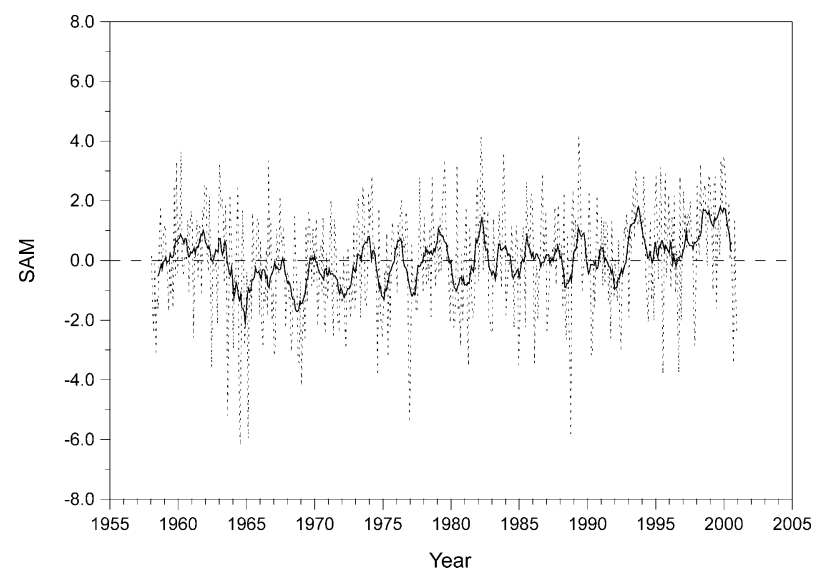

FIG. 7. The SAM as calculated from observations. Monthly data are shown as a dotted line and a running 12-month filter as a full line. and consequently significant at $<1 \%$ rather than the $<10 \%$ level. Furthermore, the NNR data demonstrate trends in every season that are statistically significant, most at the $<1 \%$ level with summer being at the $<5 \%$ level. In contrast, none of the equivalent seasonal trends derived from observations are statistically significant, although all are positive except in spring [SeptemberOctober-November (SON)], when no trend exists.

The impact of the small trend in the positive bias in the proxy zonal mean with MSLP at $65^{\circ} \mathrm{S}$ was examined by also calculating equivalent trends from the NNR using the true zonal mean data. Table 3 reveals that the magnitude of the annual and three seasonal trends are indeed reduced slightly as compared to the proxy zonal mean counterparts. Nevertheless, the trends remain much greater and more statistically significant than those derived from observations. Note that in the ECMWF datasets there is actually a very slight negative bias in the proxy zonal mean with MSLP at $65^{\circ} \mathrm{S}$; therefore, it is not feasible to even suggest a sign for any possible bias in the observational trends.

In the NNR data the largest seasonal trend is in winter while in the observations it is in summer. The former result is not surprising given that winter has the biggest trend in the zonal MSLP at $65^{\circ} \mathrm{S}$ in this dataset, the latitude of greatest change in the NNR (Hines et al. 2000). The latter observation agrees with Thompson and Solomon (2002) who, using radiosonde data from several Antarctic stations for 1969-98 including Mirny and Casey, showed the greatest decrease in near-surface pressure to be in summer continuing into autumn, the second largest seasonal trend in Table 3 derived from observations. Summer has the least significant trend in the NNR data, with a magnitude similar to spring and only half that shown by the winter data, but is closest to the equivalent seasonal trend in the observational data. Thus, the reduction in the significant positive bias in NNR MSLP in winter, and to a lesser extent the equinoctial seasons, has led to both the exaggerated increase in the trend in the difference between MSLP at $40^{\circ}$ and $65^{\circ} \mathrm{S}$ and errors in the seasonal cycle in the magnitude of such changes.

The SAM, as defined in Eq. (1) and based on the zonal MSLP data derived from the 12 stations, is shown in Fig. 7. This reveals that the general long-term trend toward the positive phase of the SAM began in the mid1960s, following a period of positive SAM in the first half of that decade. This change is marked by the lowest (highest) smoothed MSLP values at $40^{\circ}\left(65^{\circ} \mathrm{S}\right)$ in the 
1958-2000 period (cf. Fig. 3) giving the lowest values of the SAM itself. There are some indications of variability at time scales of 2-3 yr, particularly throughout the 1970s, but these are not statistically significant. The NNR-derived SAM (not shown) is broadly similar to Fig. 7 with the exception of the values prior to 1965 . The errors in the zonal MSLP at $65^{\circ} \mathrm{S}$ at this time mean that the smoothed SAM values are negative rather than positive. Bearing in mind that normalized values are utilized to define the SAM, this in turn means that the positive SAM values in the 1990s are somewhat larger and hence the resultant trend is greater. The current study indicates that for the 1958-2000 period the use of NNR data exaggerates the trend in the SAM by approximately a factor of 2 .

\section{Discussion}

This paper has attempted to ascertain the "true" changes in the SAM, if any, so that we have a benchmark against which we can examine output from GCMs in, for example, studies of the SH climate in "global warming" scenarios (e.g., Fyfe et al. 1999; Kushner et al. 2001; Stone et al. 2001). In this analysis we have employed a definition of the SAM, slightly altered from that of Gong and Wang (1999), that allows us to utilize station data to calculate the "observed" changes in this, the principal SH atmospheric mode of variability. Therefore, in contrast to most previous studies of the SAM, our findings are free of any major uncertainties caused by errors in our dataset, while potential biases in our definition of the SAM are shown to be insignificant. Using these data we conclude that during the 19582000 period there has indeed been an increase in the SAM (a shift toward its positive phase); the trend in the difference between zonal MSLP at $40^{\circ}$ and $65^{\circ} \mathrm{S}$ is statistically significant at the $<10 \%$ level. This trend has been occurring since the mid-1960s until the present day. One potential cause of the abrupt downward spike in the SAM in 1964, prior to this positive trend, is the Agung eruption of the previous year. This had a greater negative impact on tropospheric temperatures in the southern midlatitudes than the high latitudes (Angell 1988; cf. Fig. 2), which would act to weaken poleward geopotential gradients and thus decrease the strength of the SAM.

Although difficult to see in the SAM itself (Fig. 7) because of the normalizsation of the data, the plots of the individual zonal MSLP datasets (Fig. 3) indicate that the greatest change has occurred since the late 1970s, a feature also demonstrated by a SAM defined using Antarctic radiosonde data (Thompson and Solomon 2002). There has been an increase in MSLP at $40^{\circ} \mathrm{S}$ of $\sim 1.3 \mathrm{hPa}$ from 1980 to 2000 and a corresponding decrease of $\sim 1.9 \mathrm{hPa}$ at $65^{\circ} \mathrm{S}$. Seasonally, the largest observed change in the difference between mid- and highlatitude SH MSLP has taken place during summer, with slightly smaller trends in autumn and winter and no trend in spring. Examination of trends in the individual months from September to December shows agreement with the work of Hurrell and van Loon (1994), who described marked changes in the strength of the $\mathrm{SH}$ semiannual oscillation (SAO) coincident with the changes in the SAM reported here. The temporal distribution of SH MSLP trends in the second half of the year has delayed the weakening of the polar vortex in the austral spring. Therefore, one of the effects of the seasonal variation in the increase in the SAM since the late 1970s is a weaker SAO.

The results derived from the station observations were compared to equivalent data obtained from the NNRas widely used in past analyses of changes in the SAMand confirmed the findings of previous papers (Hines et al. 2000; Marshall and Harangozo 2000). These are that positive errors in NNR MSLP at high southern latitudes, which generally diminish through the period encompassed by this reanalysis, have led to spurious negative trends in pressure (cf. Fig. 4). This study demonstrates that these errors in the NNR have led the trend in the difference between MSLP at $40^{\circ}$ and $65^{\circ} \mathrm{S}$ to be exaggerated by a factor of 3 for the 1958-2000 period and in the SAM, in which the data are normalized, by a factor of 2. Although it was not possible to produce an observation-derived zonal MSLP at $65^{\circ} \mathrm{S}$ prior to the IGY of $1957 / 58$, it seems likely that the NNR before this time will be especially poor, as there will be virtually no measurements to constrain the apparently poor climatology at Antarctic latitudes (Kistler et al. 2001). Thus, the trend in the SAM derived by Mo (2000, her PC 1 in Fig. 2) is probably even more exaggerated because its lowest values (highest in PC 1) occur in this very early period of the NNR. Another problem noted with the NNR with regard to examining the SAM is that the seasonality of the magnitude of the MSLP trends is incorrect. The reanalysis demonstrates the largest increase in the difference in mid- and high-latitude pressures in the winter, whereas the observations reveal a maximum trend in summer. This deviation results from the largest errors in the NNR being in winter, and these have reduced in scale through time whereas the bias in summer, which is very small, has remained essentially constant. The causes of why the NNR is especially poor in winter at southern high latitudes remain unclear, and perhaps warrant a separate study. The fewer observations available to constrain the reanalysis model at this time of year - a combination of the polar night and fewer operational Antarctic bases-will be a contributing factor, while poor model physics associated with highlatitude features that have a greater climatological role in winter, such as sea ice, or seasonally dependent errors in the Antarctic surface energy balance (Hines et al. 1999) are other possible causes.

Finally, this study included the ECMWF ERA-15 and, perhaps more importantly, parts of the ERA-40 reanalyses in comparison against observations of zonal MSLP. All the reanalyses have a similarly high accuracy at 
$40^{\circ} \mathrm{S}$. Interestingly, the NNR is slightly better than ERA40 for 1958-69, while ERA-40 is better during the 1973-82 period with ERA-15 and the NNR being very similar for $1979-93$. However, it is at $65^{\circ} \mathrm{S}$ that significant differences between the ECMWF reanalyses and the NNR are most apparent. While considerable errors exist in ERA-40 in the late 1950s and early 1960s at this latitude, they are markedly reduced in comparison to the NNR. However, it is the period in the mid-1970s, with the assimilation of VTPR satellite sounder data, when the biggest improvements in ERA-40 versus the NNR are seen. The new ECMWF reanalysis data from this period gives a much better representation of zonal MSLP at $65^{\circ} \mathrm{S}$ than the NNR does in the 1990s (cf. Figs. 3 and 4). Inspection of the individual six Antarctic stations used to derive the zonal MSLP at $65^{\circ} \mathrm{S}$ shows a clear improvement in the ERA-40 representation of MSLP in the 1970 s compared to the 1960s in all but one case. Thus, this analysis reveals that ERA-40 provides an improved representation of $\mathrm{SH}$ high-latitude atmospheric circulation variability that can be used with nearly complete confidence at least as far back as 1973, and with higher confidence than the NNR right back to 1958.

Acknowledgments. I thank John King, Ian Renfrew, and John Turner for reading draft copies of this paper, and Phil Jones of the Climatic Research Unit, University of East Anglia, for supplying the data for the extratropical stations. The comments of two anonymous referees helped to clarify the text at various points.

\section{REFERENCES}

Angell, J. K., 1988: Variations and trends in tropospheric and stratospheric global temperatures, 1958-87. J. Climate, 1, 1296-1313.

Baldwin, M. P., 2001: Annular modes in global daily surface pressure. Geophys. Res. Lett., 28, 4115-4118.

Bland, J. M., and D. G. Altman, 1986: Statistical methods for assessing agreement between two methods of clinical measurement. The Lancet, i, 307-310.

Bromwich, D. H., A. N. Rogers, P. Kållberg, R. I. Cullather, J. W. C. White, and K. J. Kreutz, 2000: ECMWF analyses and reanalyses depiction of ENSO signal in Antarctic precipitation. $J$. Climate, 13, 1406-1420.

Fyfe, J. C., G. J. Boer, and G. M. Flato, 1999: The Arctic and Antarctic oscillations and their projected changes under global warming. Geophys. Res. Lett., 26, 1601-1604.

Gibson, R., P. Kållberg, and S. Uppala, 1996: The ECMWF re-analysis (ERA) project. ECMWF Newsletter, No. 73, 7-17.

Gong, D., and S. Wang, 1999: Definition of Antarctic oscillation index. Geophys. Res. Lett., 26, 459-462.

Hall, A., and M. Visbeck, 2002: Synchronous variability in the Southern Hemisphere atmosphere, sea ice, and ocean resulting from the annular mode. J. Climate, 15, 3043-3057.

Hines, K. M., R. W. Grumbine, D. H. Bromwich, and R. I. Cullather, 1999: Surface energy balance of the NCEP MRF and NCEPNCAR reanalysis in Antarctic latitudes during FROST. Wea. Forecasting, 14, 851-866.

, D. H. Bromwich, and G. J. Marshall, 2000: Artificial surface pressure trends in the NCEP-NCAR reanalysis over the Southern Ocean and Antarctica. J. Climate, 13, 3940-3952.

Hurrell, J. W., and H. van Loon, 1994: A modulation of the atmospheric annual cycle in the Southern Hemisphere. Tellus, 46A, 325-338.

Kalnay, E., and Coauthors, 1996: The NCEP/NCAR 40-Year Reanalysis Project. Bull. Amer. Meteor. Soc., 77, 437-441.

Karoly, D. J., P. Hope, and P. D. Jones, 1996: Decadal variations of the Southern Hemisphere circulation. Int. J. Climatol., 16, 723 738.

Kidson, J. W., 1999: Principal modes of Southern Hemisphere lowfrequency variability obtained from NCEP-NCAR reanalyses. J. Climate, 12, 2808-2830.

King, J. C., and J. Turner, 1997: Antarctic Meteorology and Climatology. Cambridge University Press, $409 \mathrm{pp}$.

Kistler, R., and Coauthors, 2001: The NCEP-NCAR 50-Year Reanalysis: Monthly means CD-ROM and documentation. Bull. Amer. Meteor. Soc., 82, 247-267.

Kushner, P. J., I. M. Held, and T. L. Delworth, 2001: Southern Hemisphere atmospheric circulation response to global warming. $J$. Climate, 14, 2238-2249.

Kwok, R., and J. C. Comiso, 2002: Spatial patterns of variability in Antarctic surface temperature: Connections to the Southern Hemisphere Annular Mode and the Southern Oscillation. Geophys. Res. Lett., 29, 1705, doi:10.1029/2002GL015415.

Limpasuvan, V., and D. L. Hartmann, 1999: Eddies and the annular modes of climate variability. Geophys. Res. Lett., 26, 3133-3136.

Marshall, G. J., 2002a: Analysis of recent circulation and thermal advection change on the northern Antarctic Peninsula. Int. J. Climatol., 22, 1557-1567.

- 2002b: Trends in Antarctic geopotential height and temperature: A comparison between radiosonde and NCEP-NCAR reanalysis data. J. Climate, 15, 659-674.

— reanalysis MSLP data viability for climate studies in the South Pacific. Geophys. Res. Lett., 27, 3057-3060.

Mo, K. C., 2000: Relationships between low-frequency variability in the Southern Hemisphere and sea surface temperature anomalies. J. Climate, 13, 3599-3610.

Palmer, T. N., 1999: A nonlinear dynamical perspective on climate prediction. J. Climate, 12, 575-591.

Polvani, L. M., and P. J. Kushner, 2002: Tropospheric response to stratospheric perturbations in a relatively simple general circulation model. Geophys. Res. Lett., 29, 1114, doi:10.1029/ 2001 GL014284.

Rogers, J. C., and H. van Loon, 1982: Spatial variability of sea level pressure and 500-mb height anomalies over the Southern Hemisphere. Mon. Wea. Rev., 110, 1375-1392.

Sexton, D. M. H., 2001: The effect of stratospheric ozone depletion on the phase of the Antarctic Oscillation. Geophys. Res. Lett., 28, 3697-3700.

Stone, D. A., A. J. Weaver, and R. J. Stouffer, 2001: Projection of climate change onto modes of atmospheric variability. J. Climate, 14, 3551-3565.

Thompson, D. W. J., and J. M. Wallace, 2000: Annular modes in the extratropical circulation. Part I: Month-to-month variability. $J$. Climate, 13, 1000-1016.

—_ and S. Solomon, 2002: Interpretation of recent Southern Hemisphere climate change. Science, 296, 895-899.

, J. M. Wallace, and G. C. Hegerl, 2000: Annular modes in the extratropical circulation. Part II: Trends. J. Climate, 13, 10181036.

Trenberth, K. E., 1984: Signal versus noise in the Southern Oscillation. Mon. Wea. Rev., 112, 326-332.

van Loon, H., J. W. Kidson, and A. B. Mullan, 1993: Decadal variation of the annual cycle in the Australian dataset. J. Climate, 6, 1227-1231.

von Storch, H., and F. W. Zwiers, 1999: Statistical Analysis in Climate Research. Cambridge University Press, 484 pp. 